\title{
Preparation and Characterization of Amphiphilic Calixarene Nanoparticles as Delivery Carriers for Paclitaxel
}

\author{
Zi-Ming Zhao, ${ }^{a, b}$ Yu Wang, ${ }^{a, b}$ Jin Han ${ }^{a, b}$ Hui-Dong Zhu, ${ }^{a}$ and Lin An*,a,b \\ ${ }^{a}$ Department of Pharmacy, Xuzhou Medical College; 209 Tongshan Road, Xuzhou 221004, P. R. China: and ${ }^{b}$ Jiangsu \\ Key Laboratory of New Drug Research and Clinical Pharmacy, Xuzhou Medical College; 209 Tongshan Road, \\ Xuzhou 221004, P.R. China.
}

Received October 1, 2014; accepted December 23, 2014

Two types of amphoteric calix[n]arene carboxylic acid (CnCA) derivative, i.e., calix[6]arene hexa-carboxylic acid $\left(\mathrm{C}_{6} \mathrm{HCA}\right)$ and calix $[8]$ arene octo-carboxylic acid $\left(\mathrm{C}_{8} \mathrm{OCA}\right)$, were synthesized by introducing acetoxyls into the hydroxyls of calix $[n]$ arene $(n=6,8) . \mathrm{C}_{6} \mathrm{HCA}$ and $\mathrm{C}_{8} \mathrm{OCA}$ nanoparticles (NPs) were prepared successfully using the dialysis method. $\mathrm{CnCA}$ NPs had regular spherical shapes with an average diameter of $180-220 \mathrm{~nm}$ and possessed negative charges of greater than $-30 \mathrm{mV}$. $\mathrm{C}_{6} \mathrm{HCA}$ and $\mathrm{C}_{8} \mathrm{OCA}$ NPs were stable in $4.5 \%$ bovine serum albumin solutions and buffers ( $\mathrm{pH} 5-9)$, with a low critical aggregation concentration value of $5.7 \mathrm{mg} \cdot \mathrm{L}^{-1}$ and $4.0 \mathrm{mg} \cdot \mathrm{L}^{-1}$, respectively. $\mathrm{C}_{6} \mathrm{HCA}$ and $\mathrm{C}_{8} \mathrm{OCA}$ NPs exhibited good paclitaxel (PTX) loading capacity, with drug loading contents of $7.5 \%$ and $8.3 \%$, respectively. The overall in vitro release behavior of PTX from the $\mathrm{CnCA}$ NPs was sustained, and $\mathrm{C}_{8} \mathrm{OCA}$ NPs had a slower release rate compared with $\mathrm{C}_{6} \mathrm{HCA}$ NPs. These favorable properties of CnCA NPs make them promising nanocarriers for tumortargeted drug delivery.

Key words calix $[n]$ arene carboxylic acid; nanoparticle; paclitaxel; tumor therapy

Paclitaxel (PTX) is a well-known anticancer drug that is used primarily to treat lung, breast and ovarian cancers. Similar to most anticancer drugs, its poor solubility in water limits the clinical applications of PTX. Taxol, a widely used clinical formulation of paclitaxel, requires the use of Cremphor-EL as a solubilizer, which has been known to cause serious problems, including hypersensitivity reactions, neurotoxicity, and nephrotoxicity. ${ }^{1,2)}$ Moreover, the lack of selectivity of PTX results in significant toxicity to noncancerous cells and severely impacts patients' quality of life. Therefore, there is a dire need for the development of a novel formulation that improves the solubility of PTX and decreases its side effects.

Among various alternatives, nano-sized drug delivery system (nano-DDS) is one of the best choices. Nano-DDS not only greatly enhances the solubility of PTX without side effects, but it also promotes intra-tumoral drug accumulation through the enhanced permeability and retention (EPR) effect. $^{3,4)}$ Many nano-DDSs of PTX have been reported, and some of them have been marketed. Abraxane, a nanosuspension of paclitaxel encapsulated in human albumin was approved by the Food and Drug Administration (FDA) in 2005 for the treatment of metastatic breast cancer. ${ }^{5)}$ A liposomebased PTX formulation, Lipusu, has been applied for the treatment of ovarian cancer in China. ${ }^{6}$ In addition to these approved drugs, a number of PTX nano-DDSs, such as polymeric nanoparticles (NPs), ${ }^{7-9)}$ inorganic NPs, ${ }^{10)}$ nano-emulsions, ${ }^{11)}$ carbon nanotubes, ${ }^{12)}$ and nanogels, ${ }^{13)}$ have been reported in preclinical studies. Although these novel PTX nano-DDSs exhibit varying levels of success, methods for improving the safety, stability and specificity of nano-DDS still warrant further research.

Calixarenes have been used as an important class of macrocyclic host molecules in supramolecular chemistry. ${ }^{14)}$ Because of their intriguing structures and well-defined cavities, high symmetry and stability, and rich modification sites, calix- arenes have attracted enormous interest in biomedical applications including ion channel mimics, ${ }^{15)}$ enzyme mimics, ${ }^{16)}$ gene transfection vectors, ${ }^{17)}$ and agents for surface recognition of proteins. ${ }^{18)}$ They were also reported to possess antimicrobial, anticancer and anti-human immunodeficiency virus (HIV) activities. $^{19,20)}$

However, one major problem limiting the applications of calixarenes in the pharmaceutical or biomedical fields is their poor water solubility. Consequently, different hydrophilic moieties have been introduced onto the upper or lower rims of calixarenes to obtain water-soluble calixarenes. The tetracarboxylic acid of $p$-tert-butylcalix[4]arene introduced by Ungaro and colleagues was an early example of a water-soluble calixarene. ${ }^{21)}$ Shinkai et al. reported the preparation of $p$-sulfonato calix[6]arene. ${ }^{22)}$ Other anionic water-soluble derivatives containing nitro, ${ }^{23)}$ phosphonic acid, ${ }^{24)}$ and carboxyl ${ }^{25)}$ moieties emerged, and the first example of a cationic water-soluble calixarene was reported by Shinkai et al. ${ }^{26)}$ Other cationic calixarenes contain tetraalkylammonium groups and primary amines. ${ }^{27-29)}$ Neutral water-soluble calixarenes have been synthesized with sulfonamides, ${ }^{30)}$ sugars, ${ }^{31)}$ and polyoxyethylene. $^{32)}$

In the development of water-soluble calixarenes, some hydrophilic-modified calixarenes were found to exhibit amphipathy and self-assemble into nano-aggregates in aqueous solutions, which were suitable for the delivery of hydrophobic antitumor drugs. An amphiphilic tetrahexyloxy-tetra- $p$ aminocalix[4] arene $\left(\mathrm{A}_{4} \mathrm{C}_{6}\right)$ was synthesized and used as a nanoparticle delivery platform for PTX. ${ }^{33)}$ PTX-loaded $\mathrm{A}_{4} \mathrm{C}_{6}$ nanoparticles had an average diameter of $79 \pm 21 \mathrm{~nm}$ and a drug loading efficiency of approximately $6.5 \%$, and the release of PTX from $\mathrm{A}_{4} \mathrm{C}_{6}$ nanoparticles could be sustained for at least $72 \mathrm{~h}$. Amphoteric calix[8]arenes with a negatively charged sulfonated upper rim and a positively charged quaternary ammonium lower rim were synthesized and could 
form aggregates of approximately $300 \mathrm{~nm}$ in the $\mathrm{pH}$ range of 7-7.6. ${ }^{34)}$ Hydrophobic drugs, such as ciprofloxacin, could be loaded into amphoteric calix[8]arenes nano-aggregates with a loading content of $9.8 \%$. The drug release behavior was $\mathrm{pH}$ triggered due to the $\mathrm{pH}$-sensitive disassembly of the amphoteric calix[8]arenes.

Carboxyls have been conjugated to the lower rim of $p$-tertbutylcalix[4]arene or the upper rim of calix[4]arene, and the resulting calix[4]arene carboxylic acid derivatives have exhibited enhanced solubilities and outstanding cation binding abilities. $^{21,25)}$ However, studies on the application of calixarene carboxylic acid derivatives as drug carriers are not available. The aim of the present work was to develop amphiphilic calixarene carboxylic acid derivatives that can act as a promising nanosize delivery carrier for PTX. For this purpose, two types of calixarene carboxylic acid derivatives, i.e., calix[6]arene hexacarboxylic acid (abbreviated as $\mathrm{C}_{6} \mathrm{HCA}$ ) and calix[8]arene octo-carboxylic acid (abbreviated as $\mathrm{C}_{8} \mathrm{OCA}$ ), were synthesized and characterized. These calix $[n]$ arene carboxylic acid derivatives (abbreviated as $\mathrm{C} n \mathrm{CA}$ ) formed into nanoparticles using an appropriate method, and their self-assembling ability, particle size, stability, drug loading and release behavior were investigated and compared. The focus was to obtain PTXloaded nanoparticles based on calixarene carboxylic acid derivatives with the desired size range, acceptable drug loading and release profiles for further development as an anti-cancer drug delivery system.

\section{Experimental}

Materials Calix[6]arene, calix[8]arene, and PTX were purchased from TCI (Shanghai, China). Ethyl chloroacetate (99\%), pyrene (99\%), Tween 80 (pharmaceutical grade) were obtained from Aladdin Reagent (Shanghai, China). Bovine serum albumin (BSA, 98\%) was purchased from Santa Cruz (Dallas, TX, U.S.A.). Acetonitrile (chromatographic grade) was from Fisher Scientific (Waltham, MA, U.S.A.). Methanol, ethanol, dichloromethane, tetrahydrofuran (THF), hexane, $\mathrm{K}_{2} \mathrm{CO}_{3}$, NaI were all of analytical grade and purchased from Sinopharm Chemical Reagent (Shanghai, China). All other reagents were of analytical grade. Water used in this study was double distilled water.

Synthsis of Calix[n]arene Carboxylic Acids Calix $[n]-$ arene carboxylic acids were synthesized as previously described. ${ }^{35)}$ To a solution of calix $[n]$ arene $(0.5 \mathrm{mmol})$ in anhydrous acetonitrile $(50 \mathrm{~mL}), \mathrm{K}_{2} \mathrm{CO}_{3}(5 \mathrm{mmol}), \mathrm{NaI}(5 \mathrm{mmol})$, and ethyl chloroacetate $(5 \mathrm{mmol})$ were added, and the solution was refluxed with stirring under a nitrogen atmosphere for $12 \mathrm{~h}$. The reaction mixture was evaporated in a vacuum, and the residue was dissolved in dichloromethane $(10 \mathrm{~mL})$ and filtered. The filtrate was dropped into 10 -fold hexane. The precipitate was filtered and dried under a vacuum to obtain calix $[n]$ arene ester. The calix $[n]$ arene ester was dissolved in a $2: 1$ mixture of THF and water $(12 \mathrm{~mL})$, and a solution of $\mathrm{NaOH}(0.3 \mathrm{M}$, $8 \mathrm{~mL}$ ) was added. The reaction was kept at room temperature for $12 \mathrm{~h}$ and at $4^{\circ} \mathrm{C}$ for another $12 \mathrm{~h}$. The reaction liquid was filtered, and the filter cake was dried under a vacuum to obtain calix $[n]$ arene carboxylic acids.

$\mathrm{C}_{6} \mathrm{HCA}$ : white powder. IR $(\mathrm{KBr}) \mathrm{cm}^{-1}: 1600.8\left(\mathrm{COO}^{-}\right)$, 1421.4 (Ar- $\mathrm{CH}_{2}$-Ar), 1033.8 (Ar-O-C), 769.5 (Ar). ${ }^{1} \mathrm{H}-\mathrm{NMR}$ $\left(\mathrm{D}_{2} \mathrm{O}\right) \delta: 6.79(18 \mathrm{H}, \mathrm{s}, \mathrm{Ar}-\mathrm{H}), 3.93\left(12 \mathrm{H}, \mathrm{s}, \mathrm{Ar}-\mathrm{CH}_{2}-\mathrm{Ar}\right), 3.87$ $\left(12 \mathrm{H}, \mathrm{s}, \mathrm{O}-\mathrm{CH}_{2}-\right)$.
$\mathrm{C}_{8} \mathrm{OCA}$ : white powder. IR $(\mathrm{KBr}) \mathrm{cm}^{-1}: 1604.7\left(\mathrm{COO}^{-}\right)$, 1423.4 (Ar- $\mathrm{CH}_{2}-\mathrm{Ar}$ ), 1035.7 (Ar-O-C), 767.6 (Ar). ${ }^{1} \mathrm{H}-\mathrm{NMR}$ $\left(\mathrm{D}_{2} \mathrm{O}\right) \delta: 6.73(24 \mathrm{H}, \mathrm{s}, \mathrm{Ar}-\mathrm{H}), 3.95\left(16 \mathrm{H}, \mathrm{s}, \mathrm{Ar}-\mathrm{CH}_{2}-\mathrm{Ar}\right), 3.84$ $\left(16 \mathrm{H}, \mathrm{s}, \mathrm{O}-\mathrm{CH}_{2}-\right)$.

Preparation of PTX-Loaded CnCA Nanoparticles PTXloaded $\mathrm{CnCA}$ nanoparticles were prepared by a dialysis method. PTX (2.0 mg) and CnCA (20.0 mg) were dissolved in ethanol $(5 \mathrm{~mL})$ and sonicated for $30 \mathrm{~min}$ at room temperature. The ethanol solution was dialyzed (MWCO 1000) overnight against several changes of water. The resulting suspension was filtered through a membrane $(0.8 \mu \mathrm{m}$ pore $)$ to remove insoluble PTX, and the PTX-loaded CnCA nanoparticles dispersion was obtained. Blank $\mathrm{C} n \mathrm{CA}$ nanoparticles were prepared using the same method without adding PTX.

Characterization of PTX-Loaded CnCA Nanoparticles The mean size and zeta potential of the nanoparticles dispersions were determined by dynamic light scattering (DLS) technique (Nicomp ${ }^{\mathrm{TM}} 380 / \mathrm{ZLS}$, PSS, U.S.A.). The sample concentration was kept at $1.0 \mathrm{mg} \cdot \mathrm{mL}^{-1}$.

The morphology of the $\mathrm{CnCA}$ nanoparticles was examined under a transmission electron microscope (Tecnai Spirit G2 TWIN, FEI, U.S.A.). Samples were placed on carbon-coated copper grids and dehydrated at ambient temperature for transmission electron microscope (TEM) observation.

The critical aggregation concentration $(\mathrm{CAC})$ of the $\mathrm{CnCA}$ nanoparticles was determined by fluorescence spectroscopy (F4600, Shimadzu, Japan) with pyrene as a fluorescence probe. The pyrene solution in methanol $\left(5 \mu \mathrm{L}, 6.0 \times 10^{-4}\right.$ M) was added to $5 \mathrm{~mL}$ volumetric flasks and evaporated to dryness under a nitrogen atmosphere. CnCA nanoparticles dispersions at various concentrations $\left(1 \times 10^{-4}-0.1 \mathrm{mg} \cdot \mathrm{mL}^{-1}\right)$ were added and then sonicated for $1 \mathrm{~h}$ before measurement. Fluorescence emission spectra were recorded at the excitation wavelength $\left(\lambda_{\mathrm{ex}}\right)$ of $335 \mathrm{~nm}$ with a set of $5 \mathrm{~nm}$ excitation and $5 \mathrm{~nm}$ emission slits. Intensity ratio $\left(I_{373} / I_{384}\right)$ of the emission spectra was plotted against the logarithm of the concentration of $\mathrm{CnCA}$ nanoparticles and the $\mathrm{CAC}$ values of $\mathrm{C}_{6} \mathrm{HCA}$ and $\mathrm{C}_{8} \mathrm{OCA}$ were determined from the inflection point of the plot.

Stability of CnCA Nanoparticles The stabilities of $\mathrm{CnCA}$ NPs in buffers at various $\mathrm{pH}$ values and in the presence of serum proteins were investigated by monitoring the variation in particle size. The following buffers were used: acetate buffer $(\mathrm{pH} 5,0.15 \mathrm{~m})$, phosphate buffer $(\mathrm{pH} 6$ and $\mathrm{pH} 7.4$, $0.15 \mathrm{M})$, and borate buffer $(\mathrm{pH} 9,0.15 \mathrm{M}) . \mathrm{C}_{6} \mathrm{HCA}$ and $\mathrm{C}_{8} \mathrm{OCA}$ NPs were suspended in $\mathrm{pH} 5, \mathrm{pH} \mathrm{6,pH} \mathrm{7.4,} \mathrm{and} \mathrm{pH} 9$ buffers at room temperature with gentle agitation for $2 \mathrm{~h}$, and the particle sizes were measured. To examine the stability of $\mathrm{CnCA}$ NPs over storage time, $\mathrm{C}_{6} \mathrm{HCA}$ and $\mathrm{C}_{8} \mathrm{OCA}$ NPs were stored

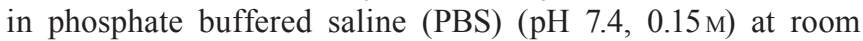
temperature for $15 \mathrm{~d}$, and the particle sizes were measured at different times. To investigate the stability of $\mathrm{CnCA}$ NPs in the presence of serum proteins, $\mathrm{C}_{6} \mathrm{HCA}$ and $\mathrm{C}_{8} \mathrm{OCA}$ NPs were suspended in a $4.5 \%$ BSA solution in PBS ( $\mathrm{pH} 7.4,0.15 \mathrm{M})$. The suspensions were incubated at $37^{\circ} \mathrm{C}, 100 \mathrm{rpm}$ for $24 \mathrm{~h}$ and determined at time intervals.

PTX Loading Capacity and Release Studies The drug loading contents and encapsulation efficiencies were determined by quantifying the paclitaxel content using HPLC analysis. Freeze-dried drug-loaded nanoparticles were sonicated in acetonitrile for $5 \mathrm{~min}$ and filtered through a membrane $(0.22 \mu \mathrm{m}$ pore). The concentration of PTX in the supernatant 
was determined by HPLC (LC-20AT, Shimadzu, Japan) using a reverse phase column (Zorbax SB-C $18,5 \mu \mathrm{m}$ pore size, $4.6 \times 250 \mathrm{~mm}$, Agilent, U.S.A.). The mobile phase was acetonitrile-water $(45: 55, \mathrm{v} / \mathrm{v})$, the flow rate was $1 \mathrm{~mL} \cdot \mathrm{min}^{-1}$ and the detection wavelength was $227 \mathrm{~nm}$. Drug loading content (LC) was calculated as a percent of the PTX mass over the total nanoparticles mass in a lyophilized sample. Drug encapsulation efficiency (EE) was calculated as a percent of the PTX mass loaded in nanoparticles relative to the mass of PTX used for the formulation.

The in vitro release of PTX from the CnCA nanoparticles was studied in the presence or absence of serum proteins using methods similar to those reported in previous studies. $^{36,37)}$ PBS $(0.15 \mathrm{M}, \mathrm{pH} 7.4)$ containing $1 \%(\mathrm{v} / \mathrm{v})$ Tween 80 was used as the medium without serum proteins, and $4.5 \%$ BSA solution in PBS $(0.15 \mathrm{M}, \mathrm{pH}$ 7.4) was used to simulate blood stream. PTX loaded $\mathrm{C} n \mathrm{CA}$ nanoparticles suspensions were mixed with an equal volume of PBS or $4.5 \%$ BSA solution. Five milliliters of these mixtures were placed in a dialysis bag (MWCO 3500) and immersed in the medium at $37^{\circ} \mathrm{C}$ under constant stirring (100 rpm). At predetermined time intervals, $0.5 \mathrm{~mL}$ of the liquid outside the bag was collected, and the same volume of fresh release medium was added. Into each sample, $0.5 \mathrm{~mL}$ acetonitrile was added and sonicated for $5 \mathrm{~min}$. After filtration through a $0.22 \mu \mathrm{m}$ membrane, the samples were measured by HPLC as described previously. The cumulative amount of released PTX was calculated by determining the total amount of drug in the release medium at time points as a percent of the drug loaded in the $\mathrm{CnCA}$ nanoparticles dispersion.

\section{Results and Discussion}

Preparation of PTX-Loaded Calixarene Nanoparticles The solubility of $\mathrm{C}_{6} \mathrm{HCA}$ and $\mathrm{C}_{8} \mathrm{OCA}$ in polar solvents, such as ethanol and acetonitrile, was improved greatly. However, despite being amphipathic, $\mathrm{C}_{6} \mathrm{HCA}$ and $\mathrm{C}_{8} \mathrm{OCA}$ were not easy to form nano-aggregates in water by stirring or sonication. Lee and colleagues prepared aminocalixarene nanoparticles using the emulsion evaporation method with the help of polyvinyl alcohol (PVA) ${ }^{33)}$ In this study, the dialysis method was found to be more suitable for the self-assembly of $\mathrm{C}_{6} \mathrm{HCA}$ and $\mathrm{C}_{8} \mathrm{OCA}$ in water. In addition, PTX could be encapsulated into $\mathrm{C}_{6} \mathrm{HCA}$ and $\mathrm{C}_{8} \mathrm{OCA}$ nanoparticles efficiently by dialysis without any stabilizing agent or surfactant. Based on their structures, the phenyl groups formed the inner hydrophobic core and the $\left(-\mathrm{O}-\mathrm{CH}_{2}-\mathrm{COOH}\right)$ chains acted as the external hydrophilic shell.

Characterization of PTX-Loaded Calixarenes Nanoparticles Nanoparticles are able to penetrate into tumor tissues, accumulate, and release drugs locally at tumor sites because of the EPR effect. Particle size is an important factor that effects the accumulation and endocytosis of nanoparticles. In general, nanoparticles with the size of less than $200 \mathrm{~nm}$ are considered to be able to penetrate through the porous blood vessels in tumors. However, Hobbs et al. reported that the pore cutoff size of porous blood vessels in majority tumors was $380-780 \mathrm{~nm}^{38)}$ Some researchers also confirmed that liposomes and nanoparticles with larger size, such as $400 \mathrm{~nm}$, could accumulate in tumors. ${ }^{39,40)}$ Therefore, it can be concluded that particles with a diameter of approximately $50-400 \mathrm{~nm}$ effectively concentrate in tumors. ${ }^{41)}$ In this study, CnCA NPs
Table 1. Particle Size and Zeta Potential of CnCA NPs and PTX Loaded $\mathrm{C} n \mathrm{CA}$ NPs $(n=3)$

\begin{tabular}{lccc}
\hline \hline Samples & $\begin{array}{c}\text { Mean diameter } \\
(\mathrm{nm})\end{array}$ & PDI & $\begin{array}{c}\text { Zeta potential } \\
(\mathrm{mV})\end{array}$ \\
\hline $\mathrm{C}_{6} \mathrm{HCA} \mathrm{NPs}$ & $222.4 \pm 34.7$ & 0.19 & $-36.2 \pm 1.5$ \\
$\mathrm{C}_{8}$ OCA NPs & $179.6 \pm 29.5$ & 0.08 & $-31.3 \pm 1.2$ \\
PTX loaded $\mathrm{C}_{6} \mathrm{HCA} N \mathrm{NP}$ & $285.4 \pm 39.9$ & 0.14 & $-35.8 \pm 1.6$ \\
PTX loaded $\mathrm{C}_{8} \mathrm{OCA} \mathrm{NPs}$ & $236.6 \pm 38.3$ & 0.13 & $-29.2 \pm 3.2$ \\
\hline
\end{tabular}

Abbreviation: PDI, polydispersity index.
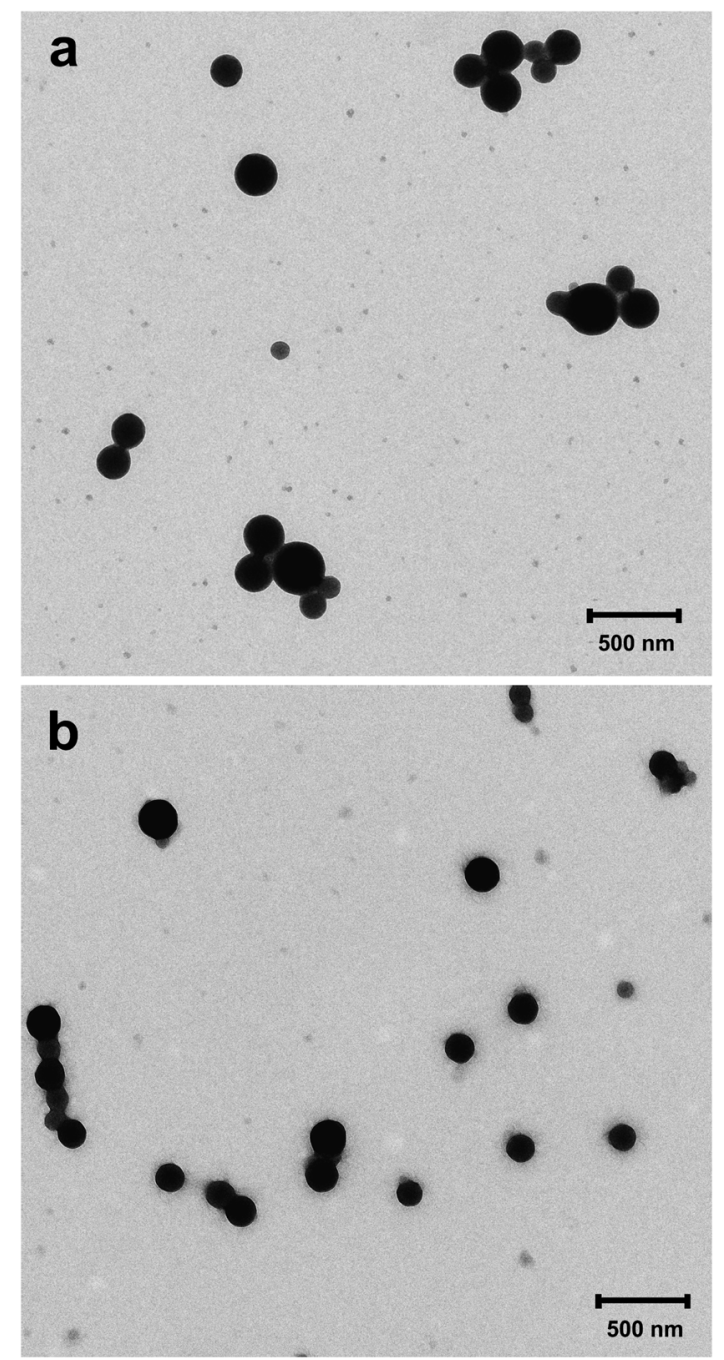

Fig. 1. TEM Images of $\mathrm{C}_{6} \mathrm{HCA}$ NPs (a) and $\mathrm{C}_{8} \mathrm{OCA} \mathrm{NPs}$ (b) in $\mathrm{pH} 7.4$ PBS

had an average hydrodynamic diameter of approximately $180-220 \mathrm{~nm}$ with mono-disperse size distribution (Table 1). The DLS results and TEM observation showed that the size of $\mathrm{C}_{8} \mathrm{OCA}$ NPs was smaller than $\mathrm{C}_{6} \mathrm{HCA}$ NPs. The decrease in size might be due to the increasing phenyl moieties that could generate stronger hydrophobic interactions between the calixarenes molecules, thus making the inner core more compact. The size difference before and after drug loading showed that the incorporation of PTX caused an increase in the size of the nanoparticles. It was most likely due to the steric hindrance of the inserted PTX, which disrupted the ordered structure of the hydrohobic core and reduced its compactness. The same 
results were observed in other studies using other types of nanoparticles and drugs. ${ }^{42,43)}$

Negative zeta potentials were obtained for the CnCA NPs, confirming the presence of carboxyl groups on the NPs' surface. The electrostatic repulsion caused by surface charges is one of the primary factors that maintain the stability of colloidal systems. Generally, colloid particles are stable when the absolute value of the zeta potential exceeds $20 \mathrm{mV}^{44)}$ The zeta potential of above $-30 \mathrm{mV}$ suggested that $\mathrm{C}_{6} \mathrm{HCA}$ and $\mathrm{C}_{8} \mathrm{OCA}$ NPs had good dispersion stability in aqueous media. Conversely, the incorporation of PTX did not significantly change the zeta potential of $\mathrm{CnCA}$ nanoparticles, suggesting that the PTX molecules had no interaction with the carboxyl groups on the surface.

As shown in the TEM images in Fig. 1, calixarene nanoparticles exhibited a spherical shape and were moderately uniform in size distribution. The particle size, as estimated by TEM, was smaller than the size measured with DLS. It is known that DLS measures the hydrodynamic diameter of the particles core along with the solvation layer attached to the particles. ${ }^{45)}$ When $\mathrm{C} n \mathrm{CA}$ nanoparticles were dispersed in water, a hydration layer formed outside the nanoparticles. However, this hydration layer was not present under TEM after sample preparation. ${ }^{46}$ Hence, the hydrodynamic diameter of $\mathrm{CnCA}$ nanoparticles was larger than the size estimated by TEM.

The fluorescence spectrum of pyrene in water exhibits five predominant peaks, and the ratio of the intensities of the first peak $\left(I_{1}\right.$ at $\left.373 \mathrm{~nm}\right)$ to the third peak $\left(I_{3}\right.$ at $\left.384 \mathrm{~nm}\right)$ can reflect the polarity of the probe's environment. ${ }^{47)}$ When nanoparticles form, there is a sudden change in the $I_{373}$ to $I_{384}$ ratio. As shown in Fig. 2, the CAC values of $\mathrm{C}_{6} \mathrm{HCA}$ and $\mathrm{C}_{8} \mathrm{OCA}$ were $5.7 \mathrm{mg} \cdot \mathrm{L}^{-1}$ and $4.0 \mathrm{mg} \cdot \mathrm{L}^{-1}$, respectively, which meant that $\mathrm{C}_{8} \mathrm{OCA}$ formed nanoparticles more easily than $\mathrm{C}_{6} \mathrm{HCA}$. This phenomenon could also be contributed to the increase in phenyl groups, which improved the stability of the nanoparticles by stronger hydrophobic interactions and thus reduced the $\mathrm{CAC}$ values. The low $\mathrm{CAC}$ value suggested that $\mathrm{CnCA}$ nanoparticles would provide good stability in solution, even after extreme dilution by a larger volume of systemic circulation in the body. ${ }^{48)}$

Stability of CnCA Nanoparticles When the environmen-

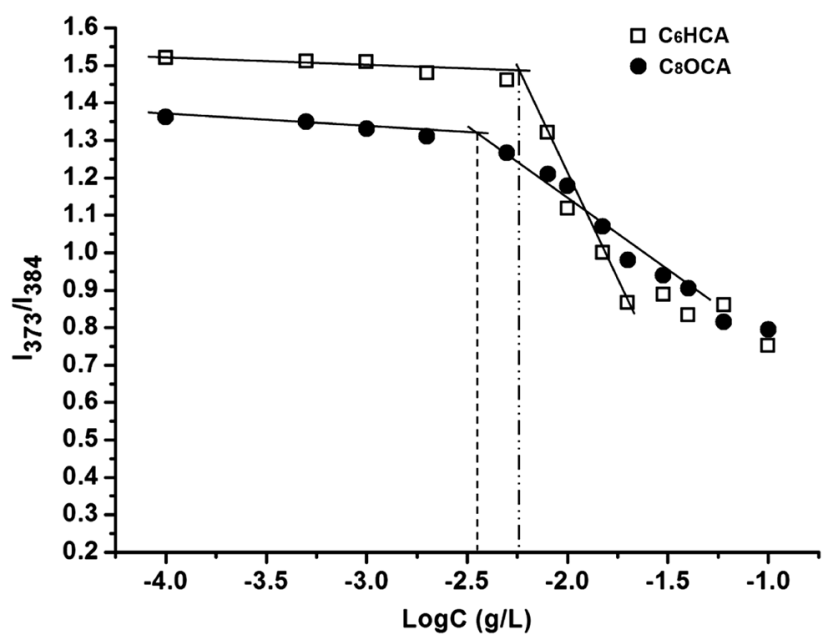

Fig. 2. Plots of Intensity Ratio $\left(I_{373} / I_{384}\right)$ from Fluorescence Emission Spectra of Pyrene versus $\log C$ of $\mathrm{C}_{6} \mathrm{HCA}$ and $\mathrm{C}_{8} \mathrm{OCA}$ tal $\mathrm{pH}$ changed from 9 to 5 , there was no significant variation in particle size. When the environmental $\mathrm{pH}$ was below 4, the size of $\mathrm{C}_{6} \mathrm{HCA}$ NPs and $\mathrm{C}_{8} \mathrm{OCA}$ NPs both increased significantly and precipitation occurred at $\mathrm{pH} 3$ (Fig. 3a). The instability and aggregation of CnCA NPs was due to the deionization of the carboxyls, which caused a rapid decrease in the electrostatic repulsion and the elimination of the hydration layer. When $\mathrm{C}_{6} \mathrm{HCA}$ NPs and $\mathrm{C}_{8} \mathrm{OCA}$ NPs were stored in $\mathrm{pH} 7.4 \mathrm{PBS}$ at room temperature, they both remained stable during 2 weeks, which indicated that $\mathrm{CnCA}$ NPs had satisfac-
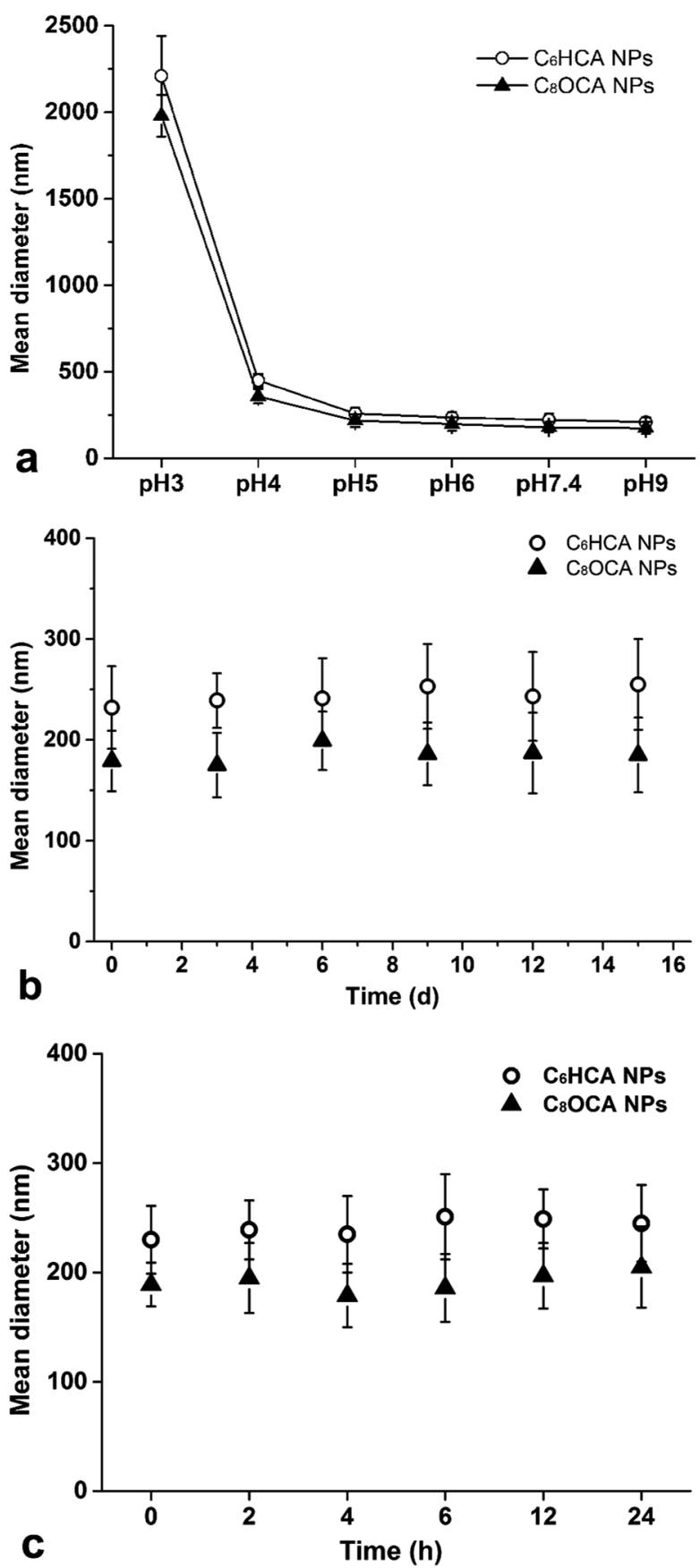

Fig. 3. (a) Effect of $\mathrm{pH}$ on the Size of $\mathrm{C}_{6} \mathrm{HCA}$ and $\mathrm{C}_{8} \mathrm{OCA}$ NPs; (b) Changes in Particle Size of $\mathrm{C}_{6} \mathrm{HCA}$ and $\mathrm{C}_{8} \mathrm{OCA}$ NPs in PBS $(0.15 \mathrm{M}, \mathrm{pH}$ 7.4) at Room Temperature; (c) Changes in Particle Size of $\mathrm{C}_{6} \mathrm{HCA}$ and $\mathrm{C}_{8}$ OCA NPs in PBS $(0.15 \mathrm{~m}, \mathrm{pH} 7.4)$ Containing $45 \mathrm{mg} \cdot \mathrm{mL}^{-1}$ BSA at $37^{\circ} \mathrm{C}, 100 \mathrm{rpm}$

Mean diameters of NPs were determined by DLS. 
tory stability in media in which they were typically stored (Fig. 3b).

Abraxane ${ }^{\circledR}$ has shown more advantages than taxol ${ }^{\circledR}$, such as higher administration dosage, better tolerability and fewer side effects. However, the pharmacokinetic properties of Abraxane ${ }^{\circledR}$ are no better than those of the Taxol ${ }^{\circledR}$ formulation. This may be due to the poor colloidal stability of Abraxane ${ }^{\circledR}$ during blood circulation. Indeed, upon intravenous (i.v.) injection and subsequent dilution in the large volume of blood, Abraxane ${ }^{\circledR}$ disassembles, allowing PTX to dissociate and resulting in a nonspecific biodistribution similar to free PTX. ${ }^{49)}$ NK105, a PTX incorporating polymeric micellar nanoparticle formulation, has markedly high plasma and tumor area under curve $(A U C)$ as compared with taxol ${ }^{\circledR}$ and Abraxane ${ }^{\circledR}$. One principal reason why NK105 exhibits higher antitumour activity is that NK105 has good stability in the bloodstream, thereby prolonging its plasma half-life. In order to be effective PTX delivery carriers, $\mathrm{CnCA}$ nanoparticles must remain intact and circulate in the blood for a sufficiently long time after intravenous injection. The interactions between $\mathrm{CnCA}$ nanoparticles and serum proteins were evaluated to predict their performance in vivo.

As a major protein in serum (approximately 60\%), albumin was utilized to evaluated the colloidal stability of nanoparticles in some studies. ${ }^{50,51)}$ A solution of BSA $\left(45 \mathrm{mg} \cdot \mathrm{mL}^{-1}\right)$ in $0.15 \mathrm{M}$ PBS $\mathrm{pH} 7.4$, which was similar to the concentration found in plasma, was prepared and mixed with $\mathrm{CnCA}$ nanoparticles. ${ }^{37)}$ The DLS results showed that the size of $\mathrm{CnCA}$ nanoparticles remained stable in BSA solution within $24 \mathrm{~h}$, suggesting that albumin adsorption is minimal. The isoelectric point of BSA is 4.7 , indicating that it is negatively charged at physiological $\mathrm{pH}$. Since $\mathrm{CnCA}$ nanoparticles have negative zeta potentials at $\mathrm{pH} 7.4$, protein adsorption to the nanoparticle surface may be limited by electrostatic repulsion. These results suggested that $\mathrm{CnCA}$ nanoparticles had good potential for drug delivery carrier by intravenous administration.

PTX Loading Capacity and Release Studies The drug loading content (LC) and entrapment efficiency (EE) of PTXloaded $\mathrm{C} n \mathrm{CA}$ NPs were determined by HPLC analysis to quantify the drug loaded in a known amount of freeze-dried nanoparticles. The EE of the $\mathrm{C}_{6} \mathrm{HCA}$ and $\mathrm{C}_{8} \mathrm{OCA}$ NPs were $81.6 \%$ and $90.3 \%$, respectively, which suggested that the dialysis method was effective for PTX loading into the inner core of the CnCA NPs. The $\mathrm{C}_{8} \mathrm{OCA}$ NPs that had a LC of $8.3 \%$ exhibited better drug loading ability than did the $\mathrm{C}_{6} \mathrm{HCA}$ NPs that had a LC of $7.5 \%$. The hydrophobic interaction between hydrophobic sites of PTX and phenyl units of calix $[n]$ arene is a key factor that influences LC. ${ }^{34)}$ Compared with $\mathrm{C}_{6} \mathrm{HCA}$ NPs, the density of phenyl units in the hydrophobic region of $\mathrm{C}_{8} \mathrm{OCA}$ NPs was higher, which indicated that there were more drug binding sites and that more PTX could be introduced into the inner core of nanoparticles. The LC of $\mathrm{C}_{8} \mathrm{OCA}$ NPs was similar to that of Abraxane $^{\circledR}$ (approximately 10\%), which suggested that the therapeutic concentration of PTX was easy to achieve using this novel nano-carrier.

The drug release from $\mathrm{CnCA}$ nanoparticles was investigated using a conventional dialysis method at a physiological temperature of $37^{\circ} \mathrm{C}$. The solubility of PTX in $1 \%$ Tween 80 is $14.5 \mu \mathrm{g} \cdot \mathrm{mL}^{-1}$, which produces a good sink condition that can solubilize more than 3 times the total amount of PTX in the dialysis bag. Figure 4 a shows the accumulative release profiles
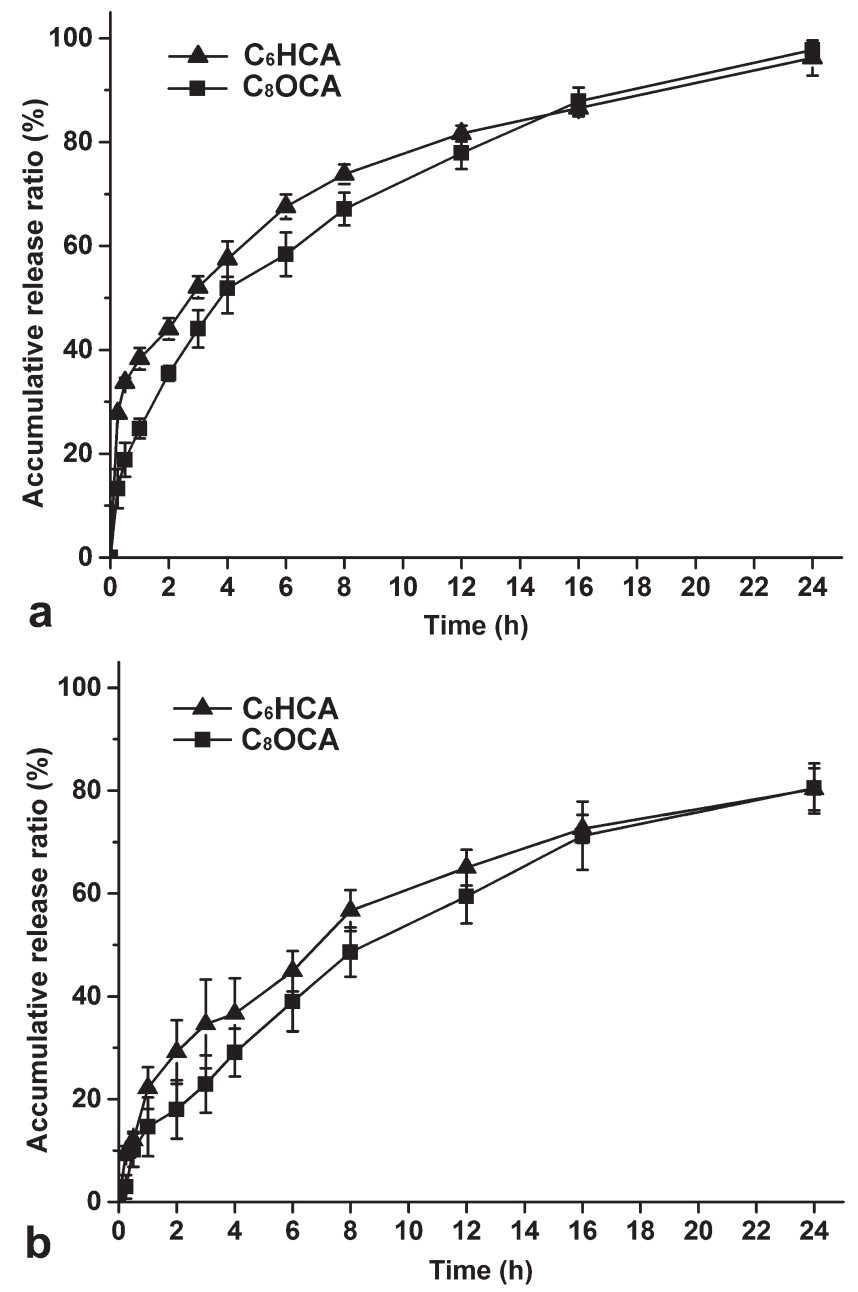

Fig. 4. The in Vitro Release Profiles of PTX-Loaded $\mathrm{C}_{6} \mathrm{HCA}$ NPs and PTX-Loaded $\mathrm{C}_{8} \mathrm{OCA}$ NPs

(a) The release profile in PBS $(0.15 \mathrm{M}, \mathrm{pH} 7.4)$ containing $1 \%$ Tween 80 at $37^{\circ} \mathrm{C}$, $100 \mathrm{rpm}$; (b) The release profile in PBS $(0.15 \mathrm{M}, \mathrm{pH} 7.4)$ containing $45 \mathrm{mg} \cdot \mathrm{mL}^{-1}$ $\mathrm{BSA}$ at $37^{\circ} \mathrm{C}, 100 \mathrm{rpm}$. Values are mean \pm S.D., $n=3$.

of PTX from $\mathrm{C}_{6} \mathrm{HCA}$ NPs and $\mathrm{C}_{8} \mathrm{OCA}$ NPs in the absence of serum proteins. The release profile of PTX- $\mathrm{C}_{6} \mathrm{HCA}$ NPs exhibited an apparent burst release of $33.7 \%$ within $30 \mathrm{~min}$. The cumulative percent drug release of $\mathrm{C}_{6} \mathrm{HCA}$ NPs at 4,8 and $24 \mathrm{~h}$ amounted to $57.5 \%, 73.8 \%$ and $96.2 \%$, respectively. The burst release of PTX- $\mathrm{C}_{8} \mathrm{OCA}$ NPs was not as notable as that of PTX- $\mathrm{C}_{6} \mathrm{HCA}$ NPs and the cumulative release percent was only $18.8 \%$ at $30 \mathrm{~min}$. The overall release rate of PTX$\mathrm{C}_{8} \mathrm{OCA}$ NPs was $5-15 \mathrm{wt} \%$ less than PTX-C 6 HCA NPs in $12 \mathrm{~h}$, and PTX could be completely released from $\mathrm{C}_{8} \mathrm{OCA}$ NPs at $24 \mathrm{~h}$. Although the release profiles of PTX loaded CnCA NPs showed a burst release within the initial period, the latter represented a slow continuous release until $24 \mathrm{~h}$, suggesting that the overall release of PTX from the CnCA NPs was sustained. This could overcome some disadvantages of PTX, such as local toxicity and a short half-life in vivo resulting from a rapid release. ${ }^{52)}$

Drug release from nanoparticles is a complicated process that can be affected by many factors, including degradation and erosion of nanoparticles matrix, diffusion process of drug, crystallinity, and the binding affinity between nanoparticles and drugs. ${ }^{53)}$ Compared with $\mathrm{C}_{6} \mathrm{HCA}$ NPs, $\mathrm{C}_{8} \mathrm{OCA}$ NPs had a minor burst release and a slower release rate, which could 
be attributed to the binding affinity between nanoparticles and drugs. As mentioned above, the higher density of phenyl groups in $\mathrm{C}_{8} \mathrm{OCA}$ NPs produced more PTX binding sites and stronger hydrophobic interactions between NPs and PTX. In comparison with $\mathrm{C}_{6} \mathrm{HCA}$ NPs, more PTX molecules were incorporated into the hydrophobic core of $\mathrm{C}_{8} \mathrm{OCA}$ NPs instead of absorbing to the particle surface. The initial burst release of PTX from the nanoparticles might be attributable to poorly entrapped PTX or PTX adsorbed onto the outside of the nanoparticles. Therefore, the burst release of PTX- $\mathrm{C}_{8} \mathrm{OCA}$ NPs was weaker than that of PTX- $\mathrm{C}_{6} \mathrm{HCA}$ NPs. The sustained release could result from the diffusion of PTX through the nanoparticles matrix, and as a consequence, PTX- $\mathrm{C}_{8} \mathrm{OCA}$ NPs with stronger hydrophobic interactions between NPs and PTX had a slower release rate.

A basic evaluation of the influence of serum proteins on the release of PTX from $\mathrm{CnCA}$ nanoparticles was conducted. As shown in Fig. 4b, the release rates of PTX from both $\mathrm{C}_{6} \mathrm{HCA}$ and $\mathrm{C}_{8} \mathrm{OCA}$ nanoparticles were significantly slower in the presence of BSA than in PBS containing 1\% Tween 80 . For example, the cumulative release percent of PTX loaded $\mathrm{C}_{8} \mathrm{OCA}$ NPs at 2,4 and $8 \mathrm{~h}$ fell from $35.5 \%, 51.8 \%$ and $67.1 \%$ to $29.2 \%, 36.6 \%$ and $56.7 \%$, respectively. The reduction of drug release could be explained by that Tween 80 was a good solubilizing agent for PTX and accelerated the release of PTX while BSA had limited solubilization and showed no significant influence on the structure of $\mathrm{C} n \mathrm{CA}$ nanoparticles. On the other hand, the BSA inside the bag could bind to free PTX after they released from the nanoparticles, resulting in fewer PTX which could cross the dialysis membrane (MWCO 3500) into the medium. As we know, albumin does not represent the full complement of proteins in blood, and these results do not adequately represent the release behavior of $\mathrm{CnCA}$ nanoparticles in vivo. Further investigation should be required to better understand and elucidate the interactions between $\mathrm{CnCA}$ nanoparticles and serum proteins.

\section{Conclusion}

In this article, amphoteric calix $[n]$ arene nanoparticles based on $\mathrm{C}_{6} \mathrm{HCA}$ and $\mathrm{C}_{8} \mathrm{OCA}$ were successfully prepared and utilized as nanocarriers of PTX. $\mathrm{C}_{6} \mathrm{HCA}$ and $\mathrm{C}_{8} \mathrm{OCA}$ NPs have regular spherical shapes with an average diameter of $180-220 \mathrm{~nm}$ and possess negative charges of more than $-30 \mathrm{mV} . \mathrm{C}_{6} \mathrm{HCA}$ and $\mathrm{C}_{8} \mathrm{OCA}$ NPs with a low CAC value of $5.7 \mathrm{mg} \cdot \mathrm{L}^{-1}$ and $4.0 \mathrm{mg} \cdot \mathrm{L}^{-1}$, respectively, are stable in $4.5 \%$ BSA solutions and buffers ( $\mathrm{pH}$ 5-9). $\mathrm{C}_{6} \mathrm{HCA}$ and $\mathrm{C}_{8} \mathrm{OCA}$ NPs exhibit good PTX loading capacity and a sustained drug release in vitro. These favorable properties of $\mathrm{CnCA}$ NPs make them a promising nanocarrier for tumor-targeted drug delivery.

Acknowledgments This work was supported by the National Natural Science Foundation of China (No. 81202490), National Natural Science Foundation of China (No. 81102381), Natural Science Foundation of Jiangsu Higher Education Institutions of China (No. 12KJB350005), Science and Technology Project of Xuzhou (No. XM12B013), Priority Academic Program Development of Jiangsu Higher Education Institutions.

Conflict of Interest The authors declare no conflict of interest.

\section{References}

1) Weiss R. B., Donehower R. C., Wiernik P. H., Ohnuma T., Gralla R. J., Trump D. L., Baker J. R. Jr., Van Echo D. A., Von Hoff D. D., Leyland-Jones B., J. Clin. Oncol., 8, 1263-1268 (1990).

2) Gelderblom H., Verweij J., Nooter K., Sparreboom A., Eur. J. Cancer, 37, 1590-1598 (2001).

3) Alexis F., Pridgen E. M., Langer R., Farokhzad O. C., Handb. Exp. Pharmacol., 197, 55-86 (2010).

4) Jain R. K., Stylianopoulos T., Nat. Rev. Clin. Oncol., 7, 653-664 (2010).

5) Micha J. P., Goldstein B. H., Birk C. L., Rettenmaier M. A., Brown J. V. III, Gynecol. Oncol., 100, 437-438 (2006).

6) Wang H., Cheng G., Du Y., Ye L., Chen W., Zhang L., Wang T., Tian J., Fu F., Mol. Med. Rep., 7, 947-952 (2013).

7) Danhier F., Lecouturier N., Vroman B., Jérôme C., Marchand-Brynaert J., Feron O., Préat V., J. Control. Release, 133, 11-17 (2009).

8) Al-Ghananeem A. M., Malkawi A. H., Muammer Y. M., Balko J. M., Black E. P., Mourad W., Romond E., AAPS PharmSciTech, 10, 410-417 (2009).

9) Wang J., Mongayt D., Torchilin V. P., J. Drug Target., 13, 73-80 (2005).

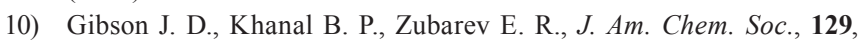
11653-11661 (2007).

11) Ganta S., Amiji M., Mol. Pharm., 6, 928-939 (2009).

12) Sobhani Z., Dinarvand R., Atyabi F., Ghahremani M., Adeli M., Int. J. Nanomedicine, 6, 705-719 (2011).

13) Lee J. Y., Kim K. S., Kang Y. M., Kim E. S., Hwang S. J., Lee H. B., Min B. H., Kim J. H., Kim M. S., Int. J. Pharm., 392, 51-56 (2010).

14) Nishimura N., Kobayashi K., Angew. Chem. Int. Ed. Engl., 47, 6258 (2008).

15) Wright A. J., Matthews S. E., Fischer W. B., Beer P. D., Chemistry, 7, 3474-3481 (2001).

16) Gutsche C. D., "Calixarenes: An Introduction," 2nd ed., Royal Society of Chemistry, Cambridge, 2008.

17) Bagnacani V., Sansone F., Donofrio G., Baldini L., Casnati A., Ungaro R., Org. Lett., 10, 3953-3956 (2008).

18) Park H. S., Lin Q., Hamilton A. D., Proc. Natl. Acad. Sci. U.S.A., 99, 5105-5109 (2002).

19) Mourer M., Duval R. E., Finance C., Regnouf-de-Vains J. B., Bioorg. Med. Chem. Lett., 16, 2960-2963 (2006).

20) Mourer M., Psychogios N., Laumond G., Aubertin A. M., Regnoufde-Vains J. B., Bioorg. Med. Chem., 18, 36-45 (2010).

21) Arduini A., Pochini A., Raverberi S., Ungaro R., J. Chem. Soc., Chem. Commun., 15, 981-982 (1984).

22) Shinkai S., Mori S., Tsubaki T., Sone T., Manabe O., Tetrahedron Lett., 25, 5315-5318 (1984).

23) Shinkai S., Tsubaki T., Sone T., Manabe O., Tetrahedron Lett., 26, 3343-3344 (1985).

24) Almi M., Arduini A., Casnati A., Pochini A., Ungaro R., Tetrahedron, 45, 2177-2182 (1989).

25) Gutsche C. D., Alam I., Tetrahedron, 44, 4689-4694 (1988).

26) Shinkai S., Shirahama Y., Tsubaki T., Manabe O., J. Chem. Soc., Perkin Trans. 1, 10, 1859-1860 (1989).

27) Arimura T., Nagasaki T., Shinkai S., Matsuda T., J. Org. Chem., 54, 3766-3768 (1989).

28) Niikura K., Anslyn E. V., J. Chem. Soc., Perkin Trans. 2, 12, 2769 2775 (1999).

29) Zadmard R., Schrader T., Angew. Chem. Int. Ed. Engl., 45, 27032706 (2006)

30) Steed J. W., Johnson C. P., Barnes C. L., Juneja R. K., Atwood J. L., Reilly S., Hollis R. L., Smith P. H., Clark D. L., J. Am. Chem. Soc., 117, 11426-11433 (1995).

31) Marra A., Scherrmann M. C., Dondoni A., Ungaro R., Casnati A., Minari P., Angew. Chem. Int. Ed. Engl., 33, 2479-2481 (1995).

32) Shi Y. H., Zhang Z. H., J. Chem. Soc., Chem. Commun., 4, 375-376 
(1994).

33) Weeden C., Hartlieb K. J., Lim L. Y., J. Pharm. Pharmacol., 64, 1403-1411 (2012)

34) Xue Y., Guan Y., Zheng A. N., Xiao H. N., Colloids Surf. B Biointerfaces, 101, 55-60 (2013).

35) Nimse S. B., Kim J., Ta V. T., Kim H. S., Song K. S., Jung C. Y., Nguyen V. T., Kim T., Tetrahedron Lett., 50, 7346-7350 (2009).

36) Kim S., Kim J. Y., Huh K. M., Acharya G., Park K., J. Control. Release, 132, 222-229 (2008).

37) Lu J., Owen S. C., Shoichet M. S., Macromolecules, 44, 6002-6008 (2011).

38) Hobbs S. K., Monsky W. L., Yuan F., Roberts W. G., Griffith L., Torchilin V. P., Jain R. K., Proc. Natl. Acad. Sci. U.S.A., 95, 46074612 (1998)

39) Yuan F., Dellian M., Fukumura D., Leunig M., Berk D. A., Torchilin V. P., Jain R. K., Cancer Res., 55, 3752-3756 (1995).

40) Choi K. Y., Min K. H., Na J. H., Choi K., Kim K., Park J. H., Kwon I. C., Jeong S. Y., J. Mater. Chem., 19, 4102-4107 (2009).

41) Yuan F., Dellian M., Fukumura D., Leunig M., Berk D. A., Torchilin V. P., Jain R. K., Cancer Res., 55, 3752-3756 (1995).

42) Ma X. W., Wang H., Jin S. B., Wu Y., Liang X. J., Int. J. Nanomedi- cine, 7, 1313-1328 (2012).

43) Mainardes R. M., Evangelista R. C., Int. J. Pharm., 290, 137-144 (2005)

44) Honary S., Zahir F., Trop. J. Pharm. Res., 12, 265-273 (2013).

45) De Palma R., Peeters S., Van Bael M. J., Van den Rul H., Bonroy K., Laureyn W., Mullens J., Borghs G., Maes G., Chem. Mater., 19, 1821-1831 (2007)

46) Pyrz W. D., Buttrey D. J., Langmuir, 24, 11350-11360 (2008).

47) Goddard E. D., Turro N. J., Kuo P. L., Ananthapadmanabhan K. P., Langmuir, 1, 352-355 (1985).

48) Xue Y. N., Huang Z. Z., Zhang J. T., Liu M., Zhang M., Huang S. W., Zhuo R. X., Polymer, 50, 3706-3713 (2009).

49) Bernabeu E., Helguera G., Legaspi M. J., Gonzalez L., Hocht C. Taira C., Chiappetta D. A., Colloids Surf. B Biointerfaces, 113, 43-50 (2014).

50) Lo C. L., Huang C. K., Lin K. M., Hsiue G. H., Biomaterials, 28 , 1225-1235 (2007).

51) Li Y. P., Pan S. R., Zhang W., Du Z., Nanotechnology, 20, 065104 (2009).

52) Huang X., Brazel C. S., J. Control. Release, 73, 121-136 (2001).

53) Mohanraj V. J., Chen Y., Trop. J. Pharm. Res., 5, 561-573 (2006). 